\title{
Enhancement of Hevea brasiliensis properties through chemical application
}

\author{
ROSZAINI KADIR and MOHD D. JANTAN \\ Biocomposite and Wood Protection Programme, Forest Product Division, Forest \\ Research Institute Malaysia/FRIM, 52109, Selangor, Malaysia \\ Manuscript received on October 10, 2015; accepted for publication on April 15, 2016
}

\begin{abstract}
The effects of four different types of bleaching agents (hydrogen peroxide, sodium hypochlorite, sodium chlorite and oxalic acid) mixed together with $2 \%$ boron-based preservative (Celbor SP) were studied on green sawn rubberwood. Two concentration levels (1\% and 2\%) of were used. Whitish values (W) and colour changes $(\Delta \mathrm{E})$ of sawn rubberwood were assessed before and after chemical treatment using a colour meter. Preliminary observation indicated that timber treated with $1 \%$ and $2 \%$ hydrogen peroxide produced better and more homogeneous colour properties. Hydrogen peroxide treated timber gave higher whitish values ( 6.23 and 9.91 for $1 \%$ and $2 \%$ solution, respectively) and lower colour changes (8.49 and 5.51 for $1 \%$ and $2 \%$ solution, respectively) when compared to the other three chemicals. Evaluation on the effects of bleaching (hydrogen peroxide with a higher level of concentration) on physical, mechanical and biological properties of rubberwood also have been determined in this study.
\end{abstract}

Key words: Hevea brasiliensis, bleaching agents, physical, mechanical, biological properties.

\section{INTRODUCTION}

Rubberwood (Hevea brasiliensis) has a multitude of applications, ranging from fuel wood to manufacturing of furniture components. To date, rubberwood industry in Malaysia has reached its mature state and this is exemplified by advances in furniture and other products manufacturing. The production of rubberwood-based items in Malaysia, a sub-sector of the timber industry, has shown optimistic progresses in the last few decades. The export values of furniture, moulding and builders carpentry and joinery $(\mathrm{BCJ})$ products made from rubberwood in 2014 were about RM8.03

Correspondence to: Roszaini Kadir

E-mail: roszaini@frim.gov.my billion, that was almost $39 \%$ of the total export of Malaysia products recorded at RM20.52 billion (MTC 2014). With this positive and encouraging development, Malaysia has emerged as the leading world producer and exporter of rubberwood-based products, mainly furniture, by strengthening its presence in the global outlook.

Despite the substantial market share of rubberwood products in terms of Malaysia's export earning, research in improving the quality of the timber is still minimal. It is envisaged that with less volume of rubberwood available in the near future, all sawn timber produced locally would be utilized to the maximum, both in terms of quality and quantity. Therefore, raw material wastage which might be due to sapstain and variation in colour 
should be kept to the minimum, as infected timber would only be suitable for low value products such as pallets and core material in plywood production. Wastage of sawn rubberwood might be minimized through quality improvement, and this could be achieved through improving sawn timber properties as demanded by the market. One property improvement that needs immediate attention is maintaining the homogeneous creamwhite colour of sawn rubberwood by applying special treatment to the timber.

Rubberwood is cream-white in colour when freshly cut. However, after treatment with boronbased preservatives, a high proportion of the sawn timber will turn pinkish, an inherent property of boron treated timber. Unless a necessary step is taken, this discolouration will be retained and most likely appear in the final products. Sometimes, due to the delay in preservative treatment and kiln drying processes, the same timber piece could be infected by sap-stain fungi causing dark colour patches on the wood surface. In the production process where stringent quality control has to be observed, there is a high probability that discoloured sawn timber and infected wood to be rejected and converted into low value products. Local rubberwood manufacturers are therefore in search of higher quality materials to meet a niche market requirement and this is echoed in their request for homogenous creamwhite rubberwood.

Light and even coloured have desired properties of wooden surface material used in furniture, moulding and BCJ products. Darker and uneven coloured rubberwood would cause problems in production processes, especially in material selection. The discolouration would degrade the quality of the raw material and ultimately the final products. The best option available to avoid the discolouration is to use a bleaching toner on the wood before the finishing process (Uysal et al. 1999a, Gerard 1983, Möttönen et al. 2005). Bleaching is an oxidation or reduction of discolouration in the structure of wood using various bleaching chemicals and bleaching systems (Ejechi and Obuekwe 1996). One important reason for bleaching is to obtain controlled surface characteristics in order to improve absorption of finishes and improvement of wood stability. In addition, bleaching of timber for furniture would bring out the character and obtain lighter and cleaner finishes.

Nevertheless, no bleaching method for solid wood has been developed that could be adapted to use on an industrial scale. Information on how bleaching changes the physical properties of solid wood as well as its mechanical strength properties is still lacking. The current bleaching technique only involved surface treatment of timber. However, discolouration and sap-stain marks in rubberwood are normally not skin deep, but penetrate throughout the cross-section of the wood block. Thus, a bleaching process whereby the bleaching agent is allowed to penetrate deep into the timber is needed, and this could be achieved through the application of vacuum-pressure treatment. The production of creamy-white colour wood coupled with better working qualities will definitely ensure strong continuous demand for rubberwood by the local wood-based industries in the future.

On the other hand, Flexner (2005) stated that there are three types of bleach used in woodworking; two-part bleach (sodium hydroxide and hydrogen peroxide) which removes the natural colour of the wood, chlorine bleach (e.g. Sodium hypochlorite or sodium chlorite) which removes the dye from the wood and oxalic acid which removes rust and water stains from the wood.

Hydrogen peroxide $\left(\mathrm{H}_{2} \mathrm{O}_{2}\right)$ is a clear, colourless liquid with no odour. It is the most powerful, satisfactory and widely used bleaching agent even though there are many other materials available (Uysal et al. 1999b). $\left(\mathrm{H}_{2} \mathrm{O}_{2}\right)$ has also been reported as a greener alternative to chlorine $\left(\mathrm{Cl}_{2}\right)$, chlorine dioxide $\left(\mathrm{ClO}_{2}\right)$ and sodium hypochlorite $(\mathrm{NaClO})$ 
that is traditionally used for bleaching colour from substances (Can and Connely 2000).

Meanwhile, $\mathrm{NaClO}$ which is a common household bleach and sodium chlorite $(\mathrm{NaClO} 2)$ are also reported as two strong oxidizing agents. When dissolved in water, it is commonly known as bleach or liquid bleach (http:/www.oxy.com/ OurBusinesses/Chemicals/Products/Document/ sodiumhypochlorite/bleach.pdf) but practically and chemically distinct from chlorine (The Chlorine Institute 2011).

Oxalic acid which is readily available in paint and hardware stores is used to diagnose and remove extractive stains. Due to easy handling and the safest bleaching agent for home use, it is preferred (http://alsnetbiz.com/homeimprovement/ oxalic_acid.html) by the customer to the others even though it can do more harm than good if not properly applied (https://www.permachink.com/ images/stories/tech-tips/Oxcon\%20Oxalic\%20 Acid-14.pdf). However, as mentioned by Herbert and Wilson (1943), the most effective bleaching involves maximizing the 2 reaction stages, i.e., oxidation of lignin and other colouring matter and oxidation of cellulose and hemicellulose to bring about development of high stable brightness, without loss in weight and least damage in strength.

The objectives of the study are (i) to evaluate the suitable bleaching agent for maintaining colour homogeneity in rubberwood and (ii) to assess the effect of bleaching on physical, mechanical and biological properties of treated rubberwood.

\section{MATERIALS AND METHODS}

Eight fresh rubberwood (Hevea brasiliensis Müll. Arg.) logs were converted into $25 \times 100 \mathrm{~mm}$ battens in FRIM's sawmill. The logs were extracted from a rubber plantation in Hulu Langat, Selangor and the clone were recorded as RRIM 605 and was further cross-cut into $600 \mathrm{~mm}$ long samples and 90 pieces of these samples which were clear of defects such as loose knots and tapping marks were chosen for chemical treatments. Fresh weight, whitish value $(\mathrm{W})$ and surface colour $(\Delta \mathrm{E})$ of each sample were recorded before treatment. Determination of whitish value and surface colour was assisted by a colourmeter@chromo-meter.

WOOD PRESERVATIVES AND BLEACHING AGENTS

Boron based preservatives (Celbor SP) were used in this study. The white powder preservative was dissolved in water to produce $2 \%$ solution strength, a preservative concentration normally used in all treatments.

Four bleaching agents were selected hydrogen peroxide $\left(\mathrm{H}_{2} \mathrm{O}_{2}\right)$, sodium hypochlorite $(\mathrm{NaClO})$, sodium chlorite $\left(\mathrm{NaClO}_{2}\right)$ and oxalic acid $\left(\mathrm{H}_{2} \mathrm{C}_{2} \mathrm{O}_{4}\right)$ at $1 \%$ and $2 \%$ concentrations. Nine chemical combinations were used in the study (Table I).

TABLE I

Combination of chemical treatment applied to $\mathrm{H}$. brasiliensis.

\begin{tabular}{cl}
\hline Combination & \multicolumn{1}{c}{ Chemical } \\
\hline 1 & Boron-based preservative $(2 \%)$, as control \\
2 & Boron-based preservative $(2 \%),+$ hydrogen peroxide $(1 \%)$ \\
3 & Boron-based preservative $(2 \%),+$ hydrogen peroxide $(2 \%)$ \\
4 & Boron-based preservative $(2 \%),+$ sodium hypochlorite $(1 \%)$ \\
5 & Boron-based preservative $(2 \%),+$ sodium hypochlorite $(2 \%)$ \\
6 & Boron-based preservative $(2 \%),+$ sodium chlorite $(1 \%)$ \\
7 & Boron-based preservative $(2 \%),+$ sodium chlorite $(2 \%)$ \\
8 & Boron-based preservative $(2 \%),+$ oxalic acid $(1 \%)$ \\
9 & Boron-based preservative $(2 \%),+$ oxalic acid $(2 \%)$ \\
\hline
\end{tabular}


Only bleaching agents that gave the best results were selected to be tested for physical and mechanical properties such as modulus of rupture, modulus of elasticity, compression parallel to grain, compression perpendicular to grain, shear parallel to grain and tension parallel to grain.

\section{PRESERVATIVE TREATMENT}

Ten replicates of wood samples were used for each boron-based preservatives and bleaching agent in combination. The wood samples were subjected to a vacuum-pressure treatment process for three hours and 10 min duration. Schedule used for the vacuum-pressure treatment is given in Table II.

TABLE II

Treatment schedule of the vacuum-pressure process.

\begin{tabular}{ll}
\hline \multicolumn{1}{c}{ Treatment phase } & \multicolumn{1}{c}{ Time } \\
\hline Initial vacuum $(-1$ bar $)$ & 30 minutes \\
Pressure period (14 bars) & 2 hours 30 minutes \\
Final vacuum (-1 bar) & 10 minutes \\
Treatment time & 3 hours 10 minutes \\
\hline
\end{tabular}

On completion of the vacuum-pressure treatment, the wood samples were removed from the treatment cylinder and their weights recorded. They were later open-stacked to air season. Evaluation of whitish value and surface colour were carried out after three days of air seasoning. The whitish value $(\mathrm{W})$ and the colour changes $(\Delta \mathrm{E})$ of treated rubberwood were calculated based on the following equations:

Whitish value $(\mathrm{W})=\left[(100-\mathrm{L})^{2}+\mathrm{a}^{2}+\mathrm{b}^{2}\right]^{1 / 2}$

Colour changes $(\Delta \mathrm{E})=\left[(\Delta \mathrm{L})^{2}+(\Delta \mathrm{a})^{2}+(\Delta \mathrm{b})^{2}\right]^{1 / 2}$

Where;

$\boldsymbol{L}^{*}=$ Fairest value (higher value indicates more whiteness)

$\boldsymbol{a}^{*}=$ "Chromaticness Index" (higher value indicates more redness)

$\boldsymbol{b} *=$ "Chromaticness Index" (higher value indicates more yellowish)

\section{PHYSICAL AND MECHANICAL TESTS}

The physical and mechanical tests were conducted according to the British Standard 373 (1957). The modulus of rupture (MOR), modulus of elasticity (MOE) and internal bonding strength (IB) of the panels were evaluated in this work. Additionally, the board density and actual moisture content were determined for all samples. Specimens with the dimensions $230 \mathrm{~mm} \times 50 \mathrm{~mm} \times 12 \mathrm{~mm}$ were tested for bending properties using center-point loading and the MOE and MOR were calculated. On the other hand, the Internal Bond (IB) test was conducted on $50 \mathrm{~mm} \times 50 \mathrm{~mm} \times 12 \mathrm{~mm}$ specimens sandwiched between two aluminum blocks. A total of 60 specimens; ten of each type of panels, was used for all tests.

\section{BIOASSAY TEST AGAINST TERMITE}

The treated rubberwood samples were subjected to no choice feeding tests according to ASTM D3345-08 (ASTM 1988) standard methods slightly modified. A subterranean termite species, Coptotermes curvignathus Holmgren was collected from active field colonies at the Forest Research Institute Malaysia (FRIM) campus using a trapping technique using a method described before (Roszaini et al. 2009). Screw-top bottles of $8 \mathrm{~cm}$ in diameter by $13 \mathrm{~cm}$ high were filled with $200 \mathrm{~g}$ of sterilized sand and $30 \mathrm{ml}$ distilled water. The bottles were left overnight to equilibrate to laboratory conditions before test initiation. One block of each timber species was placed on the surface of the damp sand and 400 termites (360 workers and 40 soldiers) were added to each bottle. All bottles were stored in an incubator maintained at $22^{\circ} \mathrm{C}$ and $65 \pm 5 \%$ relative humidity for 28 days. Within this period, if it was found that all termites appeared dead, the bottle would be taken out and the number of days until $100 \%$ mortality would be recorded. At the end of the fourth week the blocks were removed, cleaned, dried overnight and reweighed. 
The remaining live termites were weighed and recorded for each of the bottles. As detailed in the standard the condition of the test blocks were rated visually using a 1-10 scale where 10 was sound and 0 was a total failure.

\section{STATISTICAL ANALYSIS}

One way analysis of variance (ANOVA) was performed on all data to determine the significance of chemicals between treatments using MINITAB 15 computer programme. Values of $\mathrm{P}<0.05$ were considered statistically significant.

\section{RESULTS AND DISCUSSION}

\section{EFFECTS OF BLEACHING AGENTS ON COLOUR CHANGES IN RUBBERWOOD}

The mean whitish values (W) and colour changes $(\Delta \mathrm{E})$ of rubberwood after vacuum-pressure treatment with the four bleaching agents are given in Table III.

It was found that wood samples treated with $\mathrm{H}_{2} \mathrm{O}_{2}$ in $2 \%$ boron-based preservative showed the highest brightness rating compared to samples treated with the other three bleaching agents ( $\mathrm{NaClO}, \mathrm{NaClO}_{2}$ and $\mathrm{H}_{2} \mathrm{C}_{2} \mathrm{O}_{4}$ ). This was reflected by the significant increment of whiteness after vacuum-pressure treatment. Samples treated with
$1 \%$ and $2 \% \mathrm{H}_{2} \mathrm{O}_{2}$ gave higher whitish value (W) of 6.23 and 9.91 and the lowest colour changes $(\Delta \mathrm{E})$ of 8.49 and 5.51, respectively. The results indicate that $\mathrm{H}_{2} \mathrm{O}_{2}$ has a better oxidizing property than the other chemicals in removing the discolouration of freshly sawn rubberwood treated with boron-based preservatives. Zaidon et al. (2000) working on the bleaching of bamboo (Gigantochloa scortechinii) found that the bamboo strips could be bleached into whiter colour if they were boiled in $\mathrm{H}_{2} \mathrm{O}_{2}$ solution for at least 30 minutes. On the other study, Kristiansson (2012) also found that hydrogen peroxide either alone or mixed with other bleaching agents gave the best results on bleaching process of European walnut (Juglans regia), Rio rosewood (Dalbergia nigra), purpleheart (Peltogyne spp.), Honduras mahogany (Swietenia macrophylla) and padauk (Pterocarpus spp.).

Among the other three bleaching agents, wood samples treated with $\mathrm{NaClO}_{2}$ in $2 \%$ boronbased preservatives produced the poorest colour properties in terms of whiteness. $\mathrm{NaClO}_{2}$ solution at $1 \%$ and $2 \%$ gave respectively, a reading of -11.68 and -10.79 for whitish value $(\mathrm{W})$, and 17.38 and 15.39 for colour changes $(\Delta \mathrm{E})$. However, the performance to bleaching the rubberwood (whitish values) is not significant different with

TABLE III

Mean whitish value $(W)$ and colour changes $(\Delta E)$ of rubberwood before and after treatment with boron-based preservative and bleaching agents.

\begin{tabular}{lccc}
\hline \multirow{2}{*}{ Treatments } & \multicolumn{2}{c}{ Whitish value $(\mathrm{W})$} & \multirow{2}{*}{ Colour changes $(\Delta \mathrm{E})$} \\
\cline { 2 - 4 } & Before & After & \\
\hline Boron-based preservative $(2 \%)$, & $3.38(0.80)^{\mathrm{c}}$ & $-6.56(3.00)^{\mathrm{cd}}$ & $12.91(1.60)^{\mathrm{e}}$ \\
Boron-based preservative $(2 \%),+$ hydrogen peroxide $(1 \%)$ & $2.93(1.02)^{\mathrm{d}}$ & $6.23(0.71)^{\mathrm{b}}$ & $8.49(0.50)^{\mathrm{f}}$ \\
Boron-based preservative $(2 \%),+$ hydrogen peroxide $(2 \%)$ & $4.02(0.48)^{\mathrm{ab}}$ & $9.91(0.38)^{\mathrm{a}}$ & $5.51(0.49)^{\mathrm{g}}$ \\
Boron-based preservative $(2 \%),+$ sodium hypochlorite $(1 \%)$ & $4.47(0.51)^{\mathrm{a}}$ & $-8.01(1.8)^{\mathrm{d}}$ & $13.71(1.60)^{\mathrm{d}}$ \\
Boron-based preservative $(2 \%),+$ sodium hypochlorite $(2 \%)$ & $3.19(0.66)^{\mathrm{cd}}$ & $-4.90(4.90)^{\mathrm{c}}$ & $13.68(1.71)^{\mathrm{de}}$ \\
Boron-based preservative $(2 \%),+$ sodium chlorite $(1 \%)$ & $4.33(0.51)^{\mathrm{a}}$ & $-11.68(1.5)^{\mathrm{e}}$ & $17.38(1.33)^{\mathrm{a}}$ \\
Boron-based preservative $(2 \%),+$ sodium chlorite $(2 \%)$ & $3.95(0.41)^{\mathrm{b}}$ & $-10.79(1.1)^{\mathrm{e}}$ & $15.39(0.87)^{\mathrm{cd}}$ \\
Boron-based preservative $(2 \%),+$ oxalic acid $(1 \%)$ & $3.59(0.79)^{\mathrm{c}}$ & $-10.71(2.9)^{\mathrm{e}}$ & $16.77(1.91)^{\mathrm{b}}$ \\
Boron-based preservative $(2 \%),+$ oxalic acid $(2 \%)$ & $3.98(0.69)^{\mathrm{b}}$ & $-9.97(2.1)^{\mathrm{de}}$ & $14.26(2.16)^{\mathrm{d}}$ \\
\hline
\end{tabular}

Mean $( \pm$ SD) of 10 replicates for each species. Values followed by the same letter are not significantly different in the same group at the 0.05 level of probability. 
$1 \%$ and $2 \%$ of $\mathrm{H}_{2} \mathrm{C}_{2} \mathrm{O}_{4}(-10.7$ and -9.97$)$ which means that the performance of $\mathrm{NaClO}_{2}$ is almost same as $\mathrm{H}_{2} \mathrm{C}_{2} \mathrm{O}_{4}$ even though it is reported as one of the strong oxidizing agents besides NACIO (http://www.oxy.com/OurBusinesses/Chemicals/ Products/Document/sodiumhypochlorite/bleach. pdf). These reflect the performance of colour changes. Meanwhile NaCIO shows a second best as bleaching agent after $\mathrm{H}_{2} \mathrm{O}_{2}$ either in $1 \%$ or $2 \%$ solutions. The lower whitish value (W) and the higher colour changes $(\Delta \mathrm{E})$ in sawn rubberwood treated with $\mathrm{NaClO}, \mathrm{NaClO}_{2}$ and $\mathrm{H}_{2} \mathrm{C}_{2} \mathrm{O}_{4}$ might imply that these bleaching agents had somehow reduced the brightness of the samples but needs some modification i.e. other preservatives than boron, treatment method, etc.

Due to a certain chemical only reacting to a certain structural polymer in the wood (Nielsen 2007), of course performance as bleaching agents also vary according to the chemicals used.

According to Bajpai (2013), the bleaching process involves the removal of lignin (delignification) or lignin decolonization. The reaction of carbonyl groups which results in the brightening of the surface are needed in removing the lignin and this can only be done by the alkaline peroxide bleaching agent (Bhardwaj and Nguyen 2005), hydrogen peroxide. In the meantime, sodium hypochlorite which belongs to the group of chlorine is more appropriate for removing or lightening dye stains even though it is a strong oxidizer and only effective if used at a minimum of $10 \%(\mathrm{v} / \mathrm{v})$ solutions (http://oregonstate.edu/dept/larc/sites/default/ files/pdf/chlorine-fact-sheet.pdf). Nielsen (2007) reported that sodium chlorite, which reacted with a free phenolic group, is not effective as chlorine in degrading lignin and oxalic acid (called as reducing bleaches) only converts the colouring compound to a different (change it to a slight chemically different), colourless one. Jewitt (2007) also reported that oxalic acid is only good for removing wood stains formed when iron and moisture come into contact with tannic acid in the wood. Generally, the success of the bleaching operation depends on the temperature, time, chemical concentrations, and the degree of acidity or alkalinity $(\mathrm{pH})$. All these factors must keep in balance to achieve the desired degree of bleaching (Singh 1979).

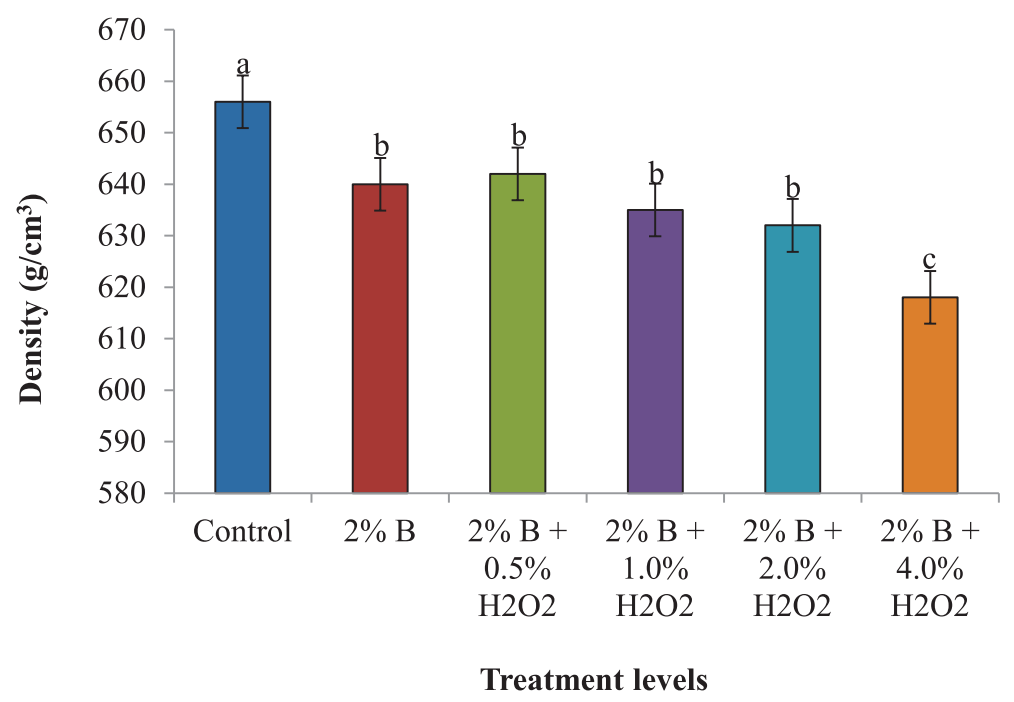

Figure 1 - Average density of rubberwood at different treatment level. Means within column followed by the same letter are not significantly different at the $5 \%$ level of ANOVA test. Error bar represents the standard error. 
EFFECTS OF BLEACHING ON PHYSICAL PROPERTIES OF RUBBERWOOD

The result of the effect of hydrogen peroxide with different concentration on wood density of rubberwood shows that with the increment of concentrations, the value of wood density decreased (Figure 1 ). The wood density decreased about $5.80 \%$ compared to control. As indicated by Bjurhager et al. (2010), $\mathrm{H}_{2} \mathrm{O}_{2}$ removed about $30 \%$ of lignin from Populus wood which affect $10 \%$ reduction of wood density. The similar trend also observed in both tobacco and Arabidopsis taliana in which the reduction of lignin from the wood had an effect on the ultrastructural architecture of the wood fibre wall (Ruel et al. 2009).

\section{EFFECTS OF BLEACHING ON MECHANICAL} PROPERTIES OF RUBBERWOOD

The mechanical properties of all samples studied are presented in Figures 2 and 3. The effects of

\section{MOE}

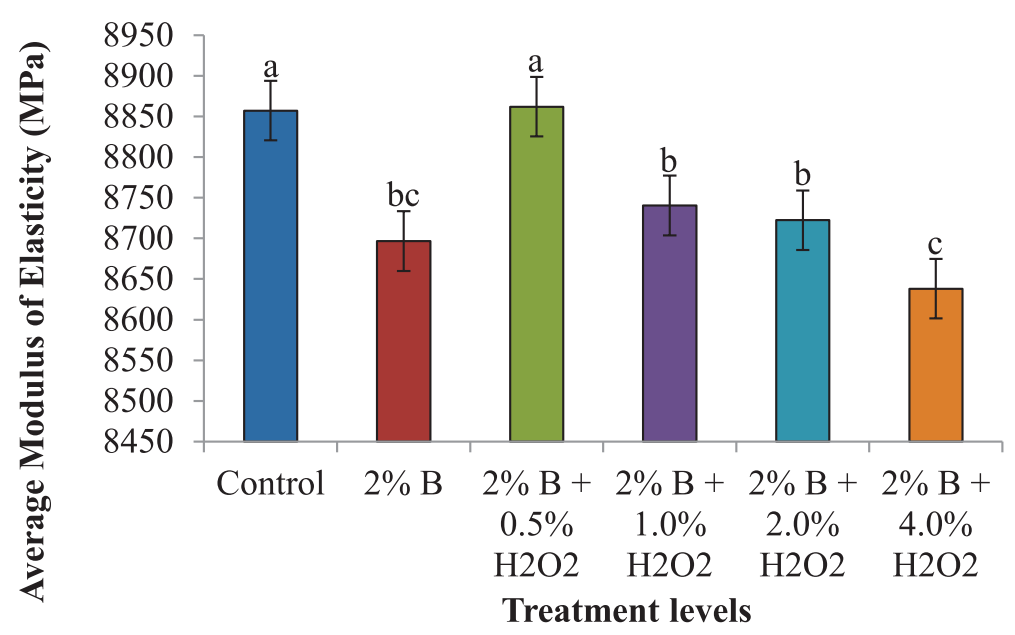

\section{MOR}

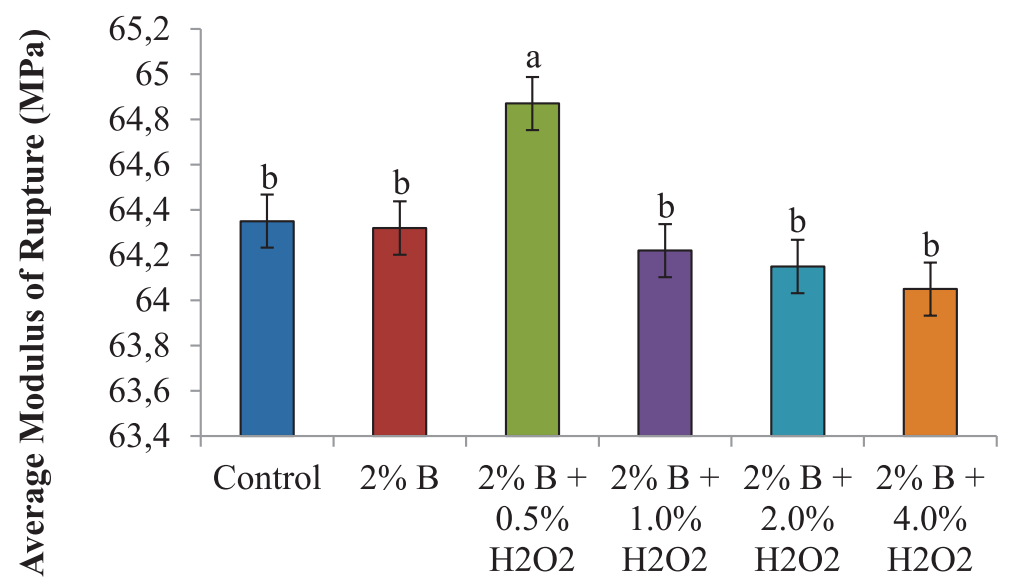

Treatment levels

Figure 2 - Average static bending (top = modulus of elasticity and bottom = modulus of rupture) of bleached rubberwood at different treatment level. Means within column followed by the same letter are not significantly different at the 5\% level of ANOVA test. Error bar represents the standard error. 


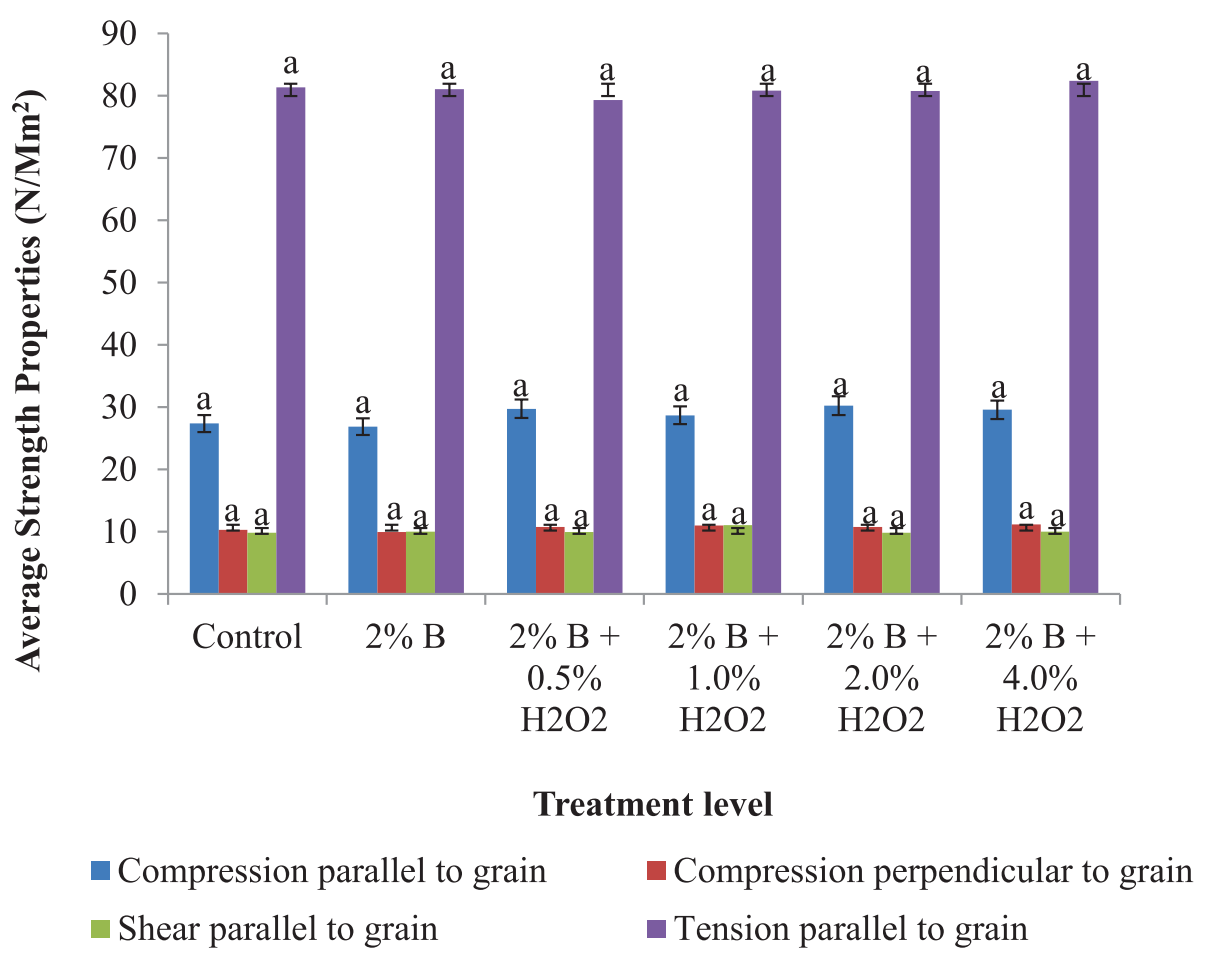

Figure 3 - Average compression parallel to grain, compression perpendicular to grain, shear parallel to grain and tension parallel to grain of bleached rubberwood at different treatment level. Means within column followed by the same letter are not significantly different at the 5\% level of ANOVA test. Error bar represents the standard error.

$\mathrm{H}_{2} \mathrm{O}_{2}$ treatment $(0.5 \%, 1.0 \%, 2.0 \%$ and $4.0 \%$ in $2 \%$ boron-based preservatives) on the mechanical properties of rubberwood were evaluated based on the "BS373: 1973 - Methods of testing small clear specimens of timber".

Results indicate that only samples treated with $2 \%$ of boron mixed with $0.5 \%$ of $\mathrm{H}_{2} \mathrm{O}_{2}$ for $\mathrm{MOE}$ did not show significant variation as compared to control. The others show a significant variation. However, the same samples show significant difference with control for MOR together with samples treated with $2 \%$ of boron mixed with $4 \%$ of $\mathrm{H}_{2} \mathrm{O}_{2}$. The highest average bleached rubberwood MOE and MOR was at $2 \%$ of the boron mixed with $0.5 \%$ of $\mathrm{H}_{2} \mathrm{O}_{2}(8922.38 \mathrm{MPa}$ and $64.87 \mathrm{MPa}$, respectively) while the lowest of both mechanical properties were at the $2 \%$ of the boron mixed with $4.0 \%$ of $\mathrm{H}_{2} \mathrm{O}_{2}$ (8638.07 MPa and 64.05 MPa, respectively). Figure 2 also shows that MOR exhibit the same pattern with MOE (except control samples) but does not show any significant variation when the level of treatment increased. However, results also showed that the trend tends to decrease when the treatment level of $\mathrm{H}_{2} \mathrm{O}_{2}$ increased to $4 \%$. This may be due to chemical reaction of the wood structure. As mentioned by Samuel (1914) and Li et al. (2011), if the chemical solution is too strong, it will decompose the wood where some of wood components such as lignin were dissolved out during the bleaching and resulted in the collapse of fiber lumens.

Shear strength and other mechanical properties results of bleached and unbleached rubberwood are summarized in Figure 3. Results showed no evidence of difference between the control samples $(0 \%)$ and the other treated samples tested either in compression parallel to grain, compression perpendicular to grain, shear or tension parallel to grain according to the one-way analysis of variance at $5 \%$ significance level. This suggests that the treatment applied to the samples did not have 
any effect in further improving the mechanical properties of the rubberwood. No difference was also detected between treatments.

\section{EFFECTS OF BLEACHING ON THE DURABILITY OF RUBBERWOOD AGAINST TERMITES}

The termite resistance performance results are summarized in Figure 4 and Table IV. The treated and untreated wood consumption by termite was based on visual ratings and mass loss following the standardized termite bio-assay and mortality are based on visual inspection. After four weeks of incubation period, the majority of the samples were found to be sound while some with slight attack were indicated by light surface nibbling.

Figure 4 shows that the treatments of rubberwood with different combination of bleaching agents with $2 \%$ of boron compound resulted in decreased weight loss when compared to control rubberwood sample (untreated). The average weight loss of control samples was $20.12 \%$, while the highest average weight loss values obtained from samples treated with $2 \%$ boron mix with $1 \% \mathrm{NaC}$ $1 \mathrm{O}$ and $2 \%$ boron mix with $1 \% \mathrm{NaClO}_{2}$ was $4.27 \%$ and $4.31 \%$, respectively. It was found that the lowest average weight loss was obtained from samples treated with $2 \%$ boron only $(2.36 \%), 2 \%$ boron mix with $1 \% \mathrm{H}_{2} \mathrm{O}_{2}(2.48 \%)$ and $2 \%$ boron mix with $2 \%$ $\mathrm{H}_{2} \mathrm{O}_{2}(2.46 \%)$. It was clear that boron mix with $2 \%$ $\mathrm{H}_{2} \mathrm{O}_{2}$ was much more effective than boron mix with $\mathrm{NaClO}, \mathrm{NaClO}_{2}$ and $\mathrm{H}_{2} \mathrm{C}_{2} \mathrm{O}_{4}$ at the $1 \%$ of chemical concentration.

It is also noticeable that increasing chemical concentrations reduced the weight loss of samples treated with all chemicals. As mentioned in previous studies (Akbulut et al. 2004, Ahmed et al. 2004), the increasing level of boron compound concentration, reduced weight loss of treated samples against termite due to the increasing of wood density. However, the increment of

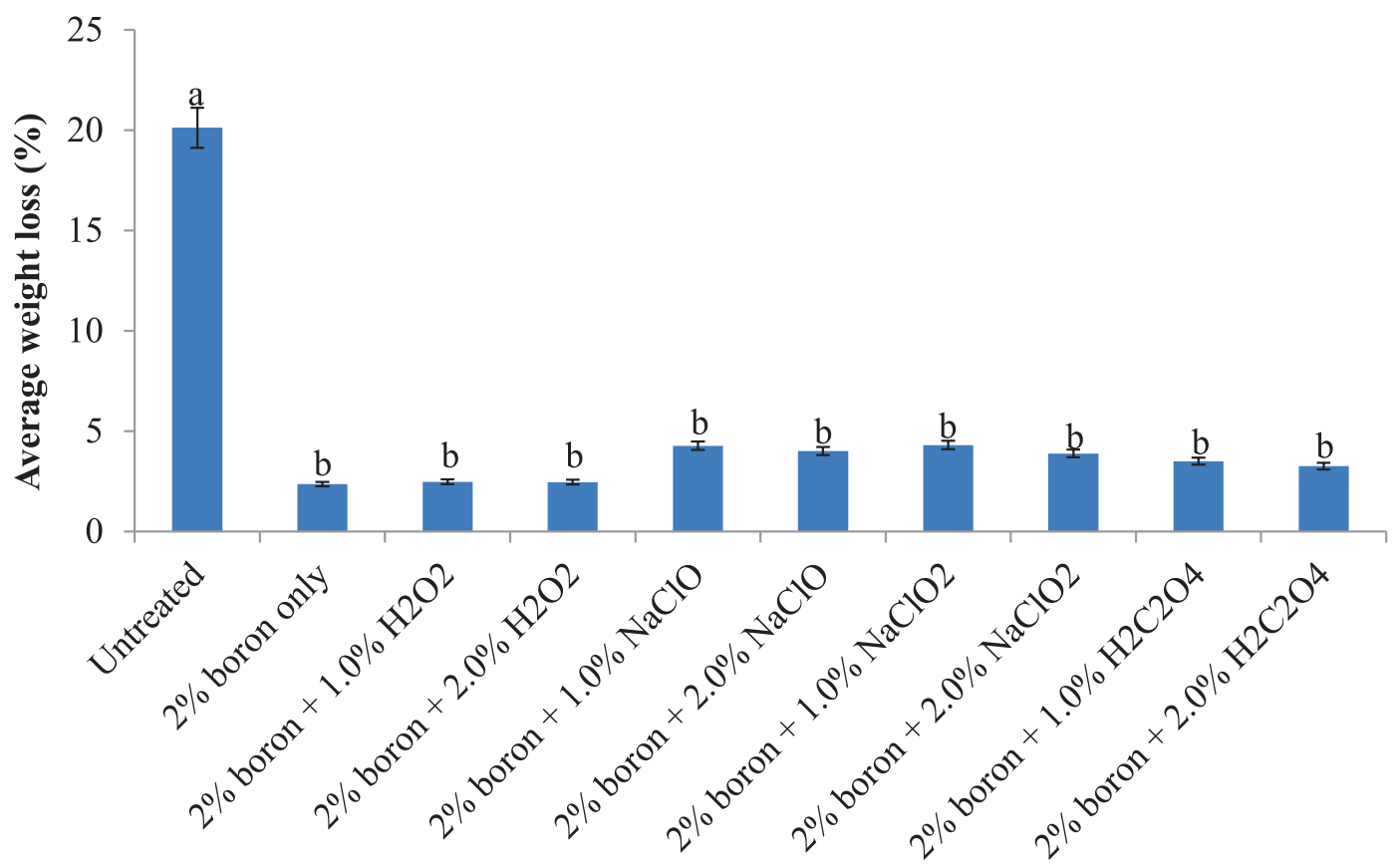

Treatments

Figure 4 - Inhibition of subterranean termite: Coptotermes curvignathus feeding by treatment of rubberwood with different of boron mixture for 28-days exposure $\left(\mathrm{H}_{2} \mathrm{O}_{2}=\right.$ Hydrogen peroxide, $\mathrm{NaCIO}=$ Sodium hypochlorite, $\mathrm{NaCIO}_{2}=$ Sodium chlorite and $\mathrm{H}_{2} \mathrm{C}_{2} \mathrm{O}_{4}=$ Oxalic acid). Means within column followed by the same letter are not significantly different at the 5\% level of ANOVA test. Error bar represents the standard error. 
TABLE IV

Average termite mortality on treated rubberwood with different treatments.

\begin{tabular}{lcccc}
\hline \multicolumn{1}{c}{ Treatments } & \multicolumn{4}{c}{ Mortality $(\%)$} \\
\cline { 3 - 5 } \cline { 3 - 5 } & 1 week & 2 weeks & 3 weeks & 4 weeks \\
\hline Untreated (control) & $0(0.00)$ & $0(0.00)$ & $16(0.63)^{\mathrm{c}}$ & $28(2.22)^{\mathrm{d}}$ \\
Boron $(2 \%)$ only & $0(0.00)$ & $63(0.63)^{\mathrm{a}}$ & $80(0.56)^{\mathrm{a}}$ & $92(0.19)^{\mathrm{ab}}$ \\
Boron $(2 \%),+\mathrm{H}_{2} \mathrm{O}_{2}(1.0 \%)$ & $0(0.00)$ & $50(1.11)^{\mathrm{a}}$ & $75(0.86)^{\mathrm{a}}$ & $97(0.00)^{\mathrm{a}}$ \\
Boron $(2 \%),+\mathrm{H}_{2} \mathrm{O}_{2}(2.0 \%)$ & $6(0.88)^{\mathrm{b}}$ & $57(0.75)^{\mathrm{a}}$ & $82(0.16)^{\mathrm{a}}$ & $98(0.12)^{\mathrm{a}}$ \\
Boron $(2 \%),+\mathrm{NaCIO}^{\mathrm{a}}(1 \%)$ & $0(0.00)$ & $42(2.22)^{\mathrm{b}}$ & $52(0.15)^{\mathrm{b}}$ & $70(1.27)^{\mathrm{c}}$ \\
Boron $\left.(2 \%),+\mathrm{NaCIO}^{\mathrm{b}} \%\right)$ & $3(0.42)^{\mathrm{c}}$ & $25(0.44)^{\mathrm{d}}$ & $48(1.56)^{\mathrm{b}}$ & $80(0.00)^{\mathrm{bc}}$ \\
Boron $(2 \%),+\mathrm{NaCIO}_{2}(1 \%)$ & $11(2.21)^{\mathrm{a}}$ & $47(0.82)^{\mathrm{b}}$ & $52(0.15)^{\mathrm{b}}$ & $83(1.12)^{\mathrm{b}}$ \\
Boron $(2 \%),+\mathrm{NaCIO}_{2}(2 \%)$ & $0(0.00)$ & $34(0.60)^{\mathrm{c}}$ & $54(0.07)^{\mathrm{b}}$ & $78(1.23)^{\mathrm{c}}$ \\
Boron $(2 \%),+\mathrm{H}_{2} \mathrm{C}_{2} \mathrm{O}_{4}(1 \%)$ & $0(0.00)$ & $51(0.03)^{\mathrm{a}}$ & $60(0.00)^{\mathrm{b}}$ & $88(2.22)^{\mathrm{b}}$ \\
Boron $(2 \%),+\mathrm{H}_{2} \mathrm{C}_{2} \mathrm{O}_{4}(2 \%)$ & $12(1.24)^{\mathrm{a}}$ & $44(0.05)^{\mathrm{b}}$ & $78(1.12)^{\mathrm{a}}$ & $93(0.54)^{\mathrm{ab}}$ \\
\hline
\end{tabular}

$\left(\mathrm{H}_{2} \mathrm{O}_{2}=\right.$ Hydrogen peroxide, $\mathrm{NaCIO}=$ Sodium hypochlorite, $\mathrm{NaCIO}_{2}=$ Sodium chlorite and $\mathrm{H}_{2} \mathrm{C}_{2} \mathrm{O}_{4}=$ Oxalic acid). Mean $( \pm \mathrm{SD})$ of 10 replicates for each species. Percentage values followed by the same letter are not significantly different in the same group at the 0.05 level of probability.

bleaching agent level concentrations increases the weight loss of test samples, even though it is not significant. This could be due to the alteration of fibre (solubilizing of lignin and reducing cellulose crystallinity) through rupture of hydrogen bonding resulted in a more open internal structure (Artz et al. 1990, Gould 1985, Larrea et al. 1997).

Besides this, combinatorial mixtures have shown synergistic activity as high mortality was observed in each combination (Table IV). Results show that all chemicals or bleaching agents were effective provided structural protection against termites. The treated rubberwood samples were found almost slightly attacked after termite exposure at the end of week 4. It was found that termite mortality was greater for all samples with boron compounds in comparison with the control rubberwood samples. At the end of the first week, only rubberwood treated with $2 \%$ boron mix with $2 \% \mathrm{H}_{2} \mathrm{O}_{2}(6 \%), 2 \%$ boron mix with $2 \% \mathrm{NaClO}$ (3\%), $2 \%$ boron mix with $1 \% \mathrm{NaClO}(11 \%)$ and $2 \%$ boron mix with $2 \% \mathrm{H}_{2} \mathrm{C}_{2} \mathrm{O}_{4}(12 \%)$ shows some effect of treatment on termite mortality. The other still had $100 \%$ survival.

On the other hand, at the end of the 4 weeks, almost complete mortalities (97\% and $98 \%$ ) were recorded in rubberwood treated with $2 \%$ boron mix with $1.0 \% \mathrm{H}_{2} \mathrm{O}_{2}$ and $2 \%$ boron mix with $2.0 \%$ $\mathrm{H}_{2} \mathrm{O}_{2}$. While the other rubberwood treatment that had termite mortality rates more than $90 \%$ can be considered as effective ( $93 \%$ for $2 \%$ boron mix with $2.0 \% \mathrm{H}_{2} \mathrm{C}_{2} \mathrm{O}_{4}$ and $92 \%$ for $2 \%$ boron only). The other two treatments at $2 \%$ of concentration only had $80 \%$ ( $2 \%$ boron mix with $2 \% \mathrm{NaCIO})$ and $78 \%\left(2 \%\right.$ boron mix with $\left.2 \% \mathrm{NaCIO}_{2}\right)$ of termite mortality. Meanwhile, the termite mortality rates at $1 \%$ of bleaching agent concentration were $70 \%$, $83 \%$ and $88 \%$ of the samples with $2 \%$ boron mix with $1 \% \mathrm{NaCIO}, 2 \%$ boron mix with $1 \% \mathrm{NaCIO}_{2}$ and $2 \%$ boron mix with $1 \% \mathrm{H}_{2} \mathrm{C}_{2} \mathrm{O}_{4}$, respectively. Only about $28 \%$ termite mortality was recorded in control samples. Generally, all the samples were equally attacked by the termites due to the various reasons such as toxic properties and efficacy of these chemicals. As can be seen from Table IV, it can be concluded that $2.5 \%$ concentrations of all the bleaching agents were sufficient to provide almost $100 \%$ termite mortality at the end of 4 weeks exposure period.

On the other hand, despite the low wood consumption, all boron- $\mathrm{H}_{2} \mathrm{O}_{2}$ treatments concentrations caused 92 to $98 \%$ mortality after 28 days incubation. Termites consumed similar $(2.36 \%)$ of the blocks treated with boron however, 
termite mortality was also considerably higher (92\%) with this treatment. It was observed that the increasing of $\mathrm{H}_{2} \mathrm{O}_{2}$ concentration did not have any significant effect on the weight loss of samples.

Higher termite mortality in wood block treated either with boron only or boron mix with $\mathrm{H}_{2} \mathrm{O}_{2}$ may be due to the effectiveness of boron itself as a termiticide (Grace et al. 2002, Lee et al. 2004, Gentz and Grace 2009). In this case, the presence of hydrogen peroxide is just as a bleaching agent only. However, previous studies reported that increasing boron compound concentration levels reduced the wood consumption / weight loss of treated samples against termites (Tsunoda et al. 2002, Lee et al. 2004, Ahmed et al. 2004, Akbulut et al. 2004).

\section{CONCLUSIONS}

a. Hydrogen peroxide is the most suitable bleaching agent in maintaining the natural colour of rubberwood (similar to a freshly sawn timber) when treated with boron-based preservative. This chemical could oxidize the discoloured rubberwood samples to produce a uniform cream-white colour, which is the preferred colour by the rubberwood manufacturers.

b. The static bending of bleached rubberwood tends to decrease when the level of hydrogen peroxide increases. However, there are no significant effects of hydrogen peroxide treatment on the other mechanical properties.

c. Biological properties increased with the growing of chemical concentrations. Boron mix with $2 \% \mathrm{H}_{2} \mathrm{O}_{2}$ was much more effective than boron mix with $\mathrm{NaClO}, \mathrm{NaClO}_{2}$ and $\mathrm{H}_{2} \mathrm{C}_{2} \mathrm{O}_{4}$ at the $1 \%$ of chemical concentration.

d. Combinatorial mixtures shown synergistic activity as high mortality of termite were observed in each combination.

\section{ACKNOWLEDGMENTS}

The authors are grateful for the support received from the Ministry of Science, Technology and
Innovation, and to Malaysia for providing funds for this study. Thanks are also due to the staff in Wood Entomology Laboratory and Timber Testing Laboratory, FRIM for helping in collecting termites and testing of the mechanical properties. This research was supported by National Science Foundation Grants IBN-9632134 and IBN0116857.

\section{REFERENCES}

AHMED BM, FRENCH JR AND VINDEN P. 2004. Evaluation of borate formulations as wood preservatives to control subterranean termites in Australia. Holzforschung 58: 446-454.

AKBULUT T, KARTAL SN AND GREEN III F. 2004. Fiberboards treated with N'-N-(1, 8-Naphtyhalyl) hydroxylamine (NHA-Na), borax, and boric acid. For Prod J 54: 59-64.

ARTZ W, WARREN C AND VILLOTA R. 1990. Tub-screw extrusion modification of a corn fiber and corn starch extruded blend. J Food Sci 55: 746-754.

ASTM - AMERICAN SOCIETY FOR TESTING AND MATERIALS. 1988. Standard test method of laboratory evaluation of wood and other cellulosic materials for resistance to termites (D3345-08). In: ASTM Annual Book of Standards. Wood. Vol. 4.10, p. 430-432.

BAJPAI P. 2013. Beach plant effluents from the pulp and paper industry. Springer Cham Heidelberg, New York Dordrecht London.

BHARDWAJ NK AND NGUYEN KL. 2005. Charges aspects of hydrogen peroxide bleached de-inked pulps. Colloids Surf A 262(1): 232-237.

BJURHAGER I, OLSSON AM, ZHANG B, GERBER L, KUMAR M, BERGLUND LA, BURGERT I, SUNDBERG B AND SALMÉN L. 2010. Ultrastructure and mechanical properties of Populus wood with reduced lignin content caused by transgenic down-regulation of Cinnamate 4-hydroxylase. Biomacromolecules 11(9): 2359-2365.

BRITISH STANDARD. 1957. Standard method of testing small clear specimen of timber. British standard 373-1957. British Standard Institution. London, $71 \mathrm{p}$.

CAN MC AND CONNELY ME. 2000. Real world cases in green chemistry. American Chemical Society: Washington, DC, 2000.

EJECHI BO AND OBUEKWE CO. 1996. Microchemical studies of wood degradation by brown rot and white rot fungi in two tropical timbers. Inter Biodeterio Biodegrad 38(2): 119-122.

FLEXNER B. 2005. Understanding wood finishing. $2^{\text {nd }}$ ed., Fox Chapel Publishing, 308 p. 
GENTZ MC AND GRACE JK. 2009. The response and recovery of the Formosan subterranean termite (Coptotermes formosanus Shiraki) from sublethal boron exposures. Inter J Pest Manage 55: 63-67.

GERARD MC. 1983. Furniture, finishing process and systems. Finishing Eastern hardwoods. Madison. USA.

GOULD M. 1985. Enhanced polysaccharide recovery from agricultural residues and perennial grasses treated with alkaline hydrogen peroxide. Biotech Bioengine 27: 893-896.

GRACE JK, WOODROW RJ AND YATES JR. 2002. Distribution and management of termites in Hawaii. Sociobiology 40: 87-93.

HERBERT TL AND WILSON WK. 1943. Photochemical stability of papers. J Res Natl Bur Stand 30, Research Paper RP1517.

JEWITT J. 2007. Using wood bleach. Furniture article. (http:// www.antiquerestorers.com/Articles/jeff/using_wood_ bleach.htm).

KRISTIANSSON L. 2012. Chemical bleaching of wood and its aging: An investigation of mahogany, walnut, rosewood, padauk and purpleheart. Bachelor Thesis. Linköping University, $24 \mathrm{p}$.

LARREA MA, GROSSMAN MVE, BELÉIA AP AND TAVARES DQ. 1997. Changes in water absorption and swollen volume in extruded alkaline peroxide pretreated rice hulls. Cer Chem 74: 98-101.

LEE S, WU Q AND SMITH WR. 2004. Formosan subterranean termite resistance of borate-modified strandboard manufactured from southern wood species: a laboratory trial. Wood Fib Sci 36: 107-118.

LI L, LEE S, LEE HK AND YOUN HJ. 2011. Hydrogen peroxide bleaching of hardwood kraft pulp with adsorbed birch xylan and its effect on paper properties. BioRes 6(1): 721-736.

MÖTTÖNEN V, ASIKAINEN A, MALVARANTA P AND ÖYKKÖNEN M. 2005. Peroxide bleaching of parquet blocks and glue lams. Holzforschung 57(1):75-80.
MTC - MALAYSIAN TIMBER COUNCIL. 2014. Annual report, 57 p. (http://mtc.com.my/wp-content/ uploads/2015/11/MTC-Annual-Report-2014.pdf).

NIELSEN S. 2007. Bleached fibres. The Taproot 13: 1-4.

ROSZAINI K, RAFEADAH R AND MOHD DAHLAN J. 2009. Durability of Malaysian timbers against the Asian subterranean termite Coptotermes gestroi Wasmann. J Insti Wood Sci 19: 16-21.

RUEL K, BERRIO-SIERRA J, DERIKVAND MM, POLLET B, THEVENIN J, LAPIERRE C, JOUANIN L AND JOSELEAU JP. 2009. Impact of CCR1 silencing on the assembly of lignified secondary walls in Arabidopsis thaliana. New Phytologist 184: 99-113.

SAMUEL JK. 1914. The mechanical properties of wood. $1^{\text {st }}$ ed., New York. J Wiley \& Sons, Inc. London, Chapman and Hall Limited, $161 \mathrm{p}$.

SINGH RP. 1979. Principles of pulp bleaching. The bleaching of pulp. $3^{\text {rd }}$ ed., Atlanta,GA TAPPI Press, p. 17.

THE CHLORINE INSTITUTE. 2011. Pamphlet 96: The sodium hypochorite manual. (http://www.chlorineinstitute. org)

TSUNODA K, WATANABE H, FUKUDA K AND HAGIO K. 2002. Effects of zinc borate on the properties of medium density fiberboard. For Prod J 52: 62-65.

UYSAL B, ALTAR M AND ÖZÇIFÇI A. 1999a. The effects of chemicals for using the bleaching of the wood surfaces on the layer harness of varnish. Tr J Agric For 23: 443-445.

UYSAL B, ATAR M AND ÖZÇIFÇI A. 1999b. The effects of wood bleaching chemicals on the bending strength of wood. Tr J Agric For 23:615-619.

ZAIDON A, RAZALI AK, MOHD NIZAM AR AND ABD. SAMAT L. 2000. Bleaching and preservative treatment of bamboo strips for bamboo-parquet products, p. 62-70. In: Komatsu K, Itoh T, Watanabe T AND Yoshimura T (Eds), Proceeding of the Third International Wood Science Symposium, Shimada M, Inoue M, Wood Research Institute, Kyoto, Japan. 